University of Nebraska - Lincoln

DigitalCommons@University of Nebraska - Lincoln

To Improve the Academy

Professional and Organizational Development Network in Higher Education

1997

WAC Revisited: An Overlooked Model for Transformative Faculty

Development

James S. Laughlin

Follow this and additional works at: https://digitalcommons.unl.edu/podimproveacad

Part of the Higher Education Administration Commons

Laughlin, James S., "WAC Revisited: An Overlooked Model for Transformative Faculty Development" (1997). To Improve the Academy. 381.

https://digitalcommons.unl.edu/podimproveacad/381

This Article is brought to you for free and open access by the Professional and Organizational Development Network in Higher Education at DigitalCommons@University of Nebraska - Lincoln. It has been accepted for inclusion in To Improve the Academy by an authorized administrator of DigitalCommons@University of Nebraska - Lincoln. 
Laughlin, J. S. (1997). WAC revisited: An overlooked model for transformative faculty development. In D. DeZure (Ed.), To Improve the Academy, Vol. 16 (pp. 165-178). Stillwater, OK: New Forums Press and the Professional and Organizational Development Network in Higher Education. Key Words: Faculty Development Programs, Faculty Development, New Faculty Programs.

\section{WAC Revisited: An Overlooked Model for Transformative Faculty Development}

\section{James S. Laughlin}

Virginia Polytechnic Institute and State University

Recently, higher education specialists have called for new faculty development initiatives, claiming current faculty development efforts need to go beyond a reductive "teaching tips" approach to consider transformative practices aimed at improving learning. While such critiques are valuable, they tend to overlook one mode of development that has had undeniable success in initiating significant individual and institutional transformations in the realms of teaching and learning. Over the past two decades, the faculty workshop in writing across the curriculum (WAC) has become a major part of successful WAC programs across the country. This article discusses how, at their best, such workshops go beyond a bag of tips for assigning and grading writing and lead faculty members through a powerful dialogic reexamination of their pedagogy. For some it is a transformative experience, resulting in wholesale changes in the ways they teach and in the ways their students learn. The article concludes by asserting that $a$ well-conceived WAC workshop continues to offer an excellent model 
for other faculty development initiatives, such as those concerned with implementing teaching technology and interdisciplinarity.

Internal and external pressures have combined in this decade to impel higher education toward a fuller commitment to improving undergraduate education. Such an institutional commitment has meant a shift of attention, energy, and, to some extent, funding toward research and development in teaching and learning. Faculty in-service support in the form of workshops or seminars on teaching effectiveness and instructional issues are one sign of this commitment to improving undergraduate education. A recent survey indicated that such workshops are offered at $90 \%$ of research universities, making them the most available in-service activity at such institutions (Crawley, 1995, p. 77).

While clearly popular, faculty development workshops are receiving increasing scrutiny and criticism. Recently, higher education specialists have called for new faculty development initiatives, claiming that many current efforts fail to go beyond a "teaching tips" approach. "Faculty development, as traditionally conceived, is relatively narrow," Qualters (1993) has claimed. Qualters has urged that we move "beyond the traditional workshops, consultations, teaching tips, and the like" (p. 45). In a similar way, Palmer (1993, p.10) warned that the "how to do it" approach to teacher training and development is reductive, preventing true dialogue on the deeper ideas and issues that can help us improve the educational exchange. The focus, such critics contend, must be on learning, and this is where faculty in-service education comes up short. As Angelo (1994) has argued, "Most faculty development efforts focus primarily on improving teachingand only secondarily, if at all, on improving learning" (p. 4).

Increasingly, faculty developers are called upon to create developmental experiences that prompt real change and growth, heightening and shifting participants' consciousness of the teaching and learning process. Qualters, for example, has suggested ways to move faculty development "out of its formative stage, in which we sought to add techniques and knowledge to a teacher's cognitive framework, to a transformative stage of examining assumptions and values that underlie teaching and the environment in which it operates"(p. 53). 
This growing interest in reconceiving faculty development to create a dynamic culture of teaching presents an important challenge for faculty developers. If we cast about for a model for this new kind of faculty development, we may just find one already in existence on many of our campuses. It is a mode of faculty development that has enjoyed undeniable success at many institutions in initiating significant individual and institutional transformations in the realms of teaching and learning.

\section{The Success of the Multi-Day WAC Workshop}

Over the past two decades, the multi-day faculty workshop (or seminar, or retreat) in writing across the curriculum (WAC) has become the major focus of WAC programs across the country. Typically, such workshops gather 15-25 faculty from a mix of disciplines to discuss the use of writing to improve teaching and learning. A central premise of WAC is that writing is a learning activity as well as a communication activity. The WAC movement advocates integrating a variety of writing experiences into the entire curriculum rather than relegating them to one or a few composition courses. WAC workshops introduce instructors to the theory and research that support this view of writing and help instructors redesign courses to include a critical written component to accelerate active learning and deepen comprehension. While some workshops are busy one-day affairs, many run from a couple of days to a week or longer. Many WAC workshops are scheduled in summer; weekend retreats during the school year are also a frequent choice. (See Appendix for a list of WAC resources.)

My own experience researching WAC programs and planning organizing, and leading week-long WAC workshops at Virginia Polytechnic Institute and State University has convinced me that such workshops offer an effective model for transformative faculty development. Faculty administrators and developers can learn important lessons by examining the approach to faculty development undertaken by well-conceived WAC workshops and the specific conditions that promote growth and transformation in workshop participants. 
Measuring transformation in teachers' theories and practices and in institutional culture is no easy task, of course. WAC literature on this issue is mostly naturalistic and testimonial in character. However, at least one quantitative study documents changes in pedagogy through contact with writing across the curriculum workshops. Fulwiler, Gorman, and Gorman (1986) reported a study in which a Writing Attitude Survey was administered Pre-Test and Post-Test to over $\mathbf{2 0 0}$ faculty participants in multi-day workshops. Responses to questions on the use of writing indicated significant changes. For instance, 63 of 221 participants who initially disagreed with or were neutral towards the statement, "Writing can play an important role in classes that enroll over 100 students," had changed to agree by the end of the workshop. While the focus here is on writing, the response indicates a significant openness to pedagogical revision. Those now accepting the possibility of using writing in large classes have been able to reconceive what is possible in terms of classroom activities, modes of learning, and student-teacher interactions. As the authors concluded, their study "demonstrates that the workshops create changes in short-term attitudes-the necessary precondition to changes in teaching pedagogy, course curricula and student writing abilities" (p. 65).

While more short- and long-term studies are needed, the abundance of testimonials offer convincing evidence for the far-reaching effects of these experiences. Here are a few representative examples:

I expected to learn specific strategies for incorporating writing in my classes and efficiencies to make grading easier. I did not anticipate being so inspired and energized to make substantial changes in all of my classes. (Participant in Virginia Tech's weeklong WAC workshop, 1996)

At that weekend workshop...I knew I had lucked into something that would change my fundamental beliefs about teaching, learning, and students (Historian Richard Straw, qtd. in Kipling and Murphy, 1992, p. 48).

WAD [Writing-Across-the-Disciplines, an alternative term for WAC] is the only experience I have had at this university that-how shall I say it-is so free and so unrestricting in terms of giving and sharing ideas. Not just about writing, but about who we are, how we teach, and 
what kind of changes we can make. I've never been in any other group that provided me this kind of experience. This is the only one where ideas are really freely flowing, and positive things coming out. This is the only one (Art historian Yoshio Kusaba, qtd. in BeMiller et. al., 1990, p. 125).

The writing workshops have helped me change the way I teach chemistry. Lectures are still a major part of the way I teach, but once students have begun to familiarize themselves with the material, writing in a notebook/journal begins... The lecture hour begins to evolve from the students themselves and the responsibility for engaging with content shifts to their reading and problem solving. The lecture hour becomes a time where guided reinterpretation and more critical thinking begin to occur within the students' minds. The course content gets displayed through their own writing -in their own symbolism and languageand they become more completely involved (Professor of Chemistry Michael Strauss, qtd. in Dickerson, Fulwiler, and Steffens, 1990, p. 51).

Sustained reflections on individuals' workshop experiences can now be found in countless pedagogical articles and conference papers produced by WAC workshop participants in all disciplines. At Virginia Tech, for example, faculty from more than a dozen different disciplines have used their WAC workshop experiences to publish articles and present papers at national conferences, with several more in the works as I write. Most often these WAC participants are discussing fundamental changes in the ways they teach and the ways their students learn. Many other WAC workshop veterans can be found working on curricular issues, training graduate teachers, establishing outreach programs, and completing a variety of other research projects that draw upon their workshop experiences.

It may seem odd to describe workshops in writing as transformative teaching events. Teachers attending WAC workshops are themselves greatly surprised to find how quickly one gets to the heart of teaching and learning when examining the function of writing. Perhaps this is because the WAC movement posits writing as a fundamental way of knowing, an essential learning activity involving the construction, as well as presentation, of knowledge. Discussions of writing seem to lead inevitably to discussions of critical thinking and critical reading, of team projects and peer review, of effective assignment design and in-class activities that address diverse learning styles, 
and on to virtually every facet of teaching and learning. As one Virginia Tech WAC workshop participant wrote on the workshop's final day, 'I've learned new approaches to ways of looking at things that will impact all my courses...even those that do not involve writing. I am very sure that this experience is going to change the way I teach."

WAC workshops are collectively contributing to a transformation in the culture of teaching. Some institutions do continue in a strong lecture mode tradition that treats students as passive recipients of teachers' knowledge and wisdom. But the WAC movement has helped to promote an alternative teaching model based on constructivist theories of learning that has come to change higher education profoundly in the 1990 s.

Changes in institutional culture as a result of WAC initiatives are difficult to gauge. But here too a sizable body of qualitative evidence supports the positive effects that writing across the curriculum activities have on the collective culture of teaching. As faculty members and administrators at California State University at Chico have declared,

we know that once an individual department or discipline has achieved a critical mass - a group of faculty who become accustomed to thinking together about writing and learning and who devote themselves to discipline-specific projects-[WAC] work begins to have the real payoff with students that we too often can only dream it will (BeMiller et al., 1990, p. 134).

Shared experiences in an extended workshop create collective support and growth, as illustrated in the following account from a teacher who experienced a "breakthrough" while attending his first WAC workshop:

Efforts to change my teaching style have been greatly assisted by the fact that all of my colleagues in the philosophy department use various notions from writing across the curriculum in both the basic and advanced courses: ungraded journals to review the material; peer reviews to improve the structure and content of the assigned, graded papers; end-of-class summaries or questions raised by the material... These changes in the philosophy department are enhanced by the increasing number of our fellow teachers across campus using similar 
methods and by the mutual support offered in the periodic workshops conducted by the WAC Committee (Magnotto et. al., 1990, pp. 73-74).

The key question remains. If the well-conceived multi-day WAC workshop is indeed a transformative faculty development experience, what are the factors and conditions that most contribute to its deep effects on participating faculty?

\section{Time to Develop Community}

I have stressed multi-day workshops because I believe that a lengthy workshop experience is an essential factor in its success. Many WAC programs have half-day or day-long workshops that can be very effective in introducing and practicing new techniques, promoting dialogue on teaching issues of concern, and renewing faculty spirits. However, it is far easier for such limited time workshops to devolve into a "dissemination model," where one or a few experts on the chosen subject present their method of doing things. While they can be quite valuable, seldom do such events give rise to transformative changes. True dialogue requires that we establish a level of comfort based on sharing, active listening, tolerance of difference, support, respect, and a sense of common purpose. Even with a full day to work, it is unlikely that most faculty will be able to step out of their busy lives and into open and productive dialogue in a group composed mostly or wholly of strangers. According to one participant in our week-long workshop, creating "truly a safe place to discuss, argue, and show concern" cannot be accomplished quickly.

The most beneficial aspect of multi-day WAC workshops, cited again and again by participants, is the establishment of real community. Multiple days together enable participants to share their backgrounds, their areas of expertise, their pedagogies, their challenges, frustrations, and uncertainties as teachers and members of specific disciplinary communities. When instructors hear other instructors from vastly different fields identify similar concerns about teaching and learning, initial surprise turns to comfort, then to a sense of connection and purpose in working toward shared goals. For many college teachers, such a workshop is their first extended period of reflection on their profession. The invitation to speak and write about 
their own teaching philosophies helps them to articulate the assumptions upon which they have built their methodologies and teaching personae. At the same time, exposure to a range of conceptualizations of what it means to teach and learn inevitably expands and challenges one's own pedagogy. One hears new and different articulations that challenge or expand one's own root assumptions.

This flow of language among those united in a focused endeavor asks participants to reimagine their own, often latent, theories of learning and teaching. As one Virginia Tech WAC participant reflected, a week of such community provided the opportunity to stretch and grow and be challenged by people in unrelated disciplines. I was able to gain ideas and common ground with people in seemingly unrelated fields." Not all of this cross-disciplinary sharing occurs during structured time. Lunch and coffee breaks not only supply needed down time, but also provide crucial spaces and times for participants to build relationships through informal interactions.

If we are to move beyond teaching tips and into reflection on fundamental questions of what it is to teach and to learn, to write and to know, extended time is essential. The mental activities involved in WAC workshops are taxing and time-consuming. Participants read pedagogy, reflect deeply on their own practice, confront new paradigms that may challenge their bedrock assumptions, reconceive how new ideas might translate into their own disciplines and their own classrooms, and work individually and in groups to revise syllabi, assignments, and whole courses. Even participants in a week-long, or multi-week workshop leave with much thinking and application work left to do. As one faculty member wrote, following a two-day workshop at Prince William Community College, "This was such a rich, informative workshop that I will need time (months? years?) to digest, synthesize, reflect upon and apply what I have been exposed to. Thank you!" (Magnotto et al., 1990, p 68).

The disequilibrium that many teachers feel as they confront new learning theories and teaching practices can, of course, lead to resistance. The multi-day workshop gives such teachers the time and supportive forum for airing and working through their concerns and frustrations. The experience of one of Virginia Tech's most distinguished teachers during one of our WAC seminars offers a case in 
point. Early on in the seminar, this professor of civil engineering heard much from seminar leaders and others in the group about the benefits of informal writing, but he could not convince himself of its merits for his discipline and his students. By mid-week, however, he was striving to incorporate writing in the framework of experiential learning. He requested a resource book on journals and read through much of it that night. By the end of the week, he presented to fellow participants an impressive theoretical justification for journal writing assignments in his upper division classes and has successfully used them ever since. Had this teacher heard discussion of the uses of informal writing in an afternoon roundtable or even a day-long workshop, it is doubtful that he would have ever expended sufficient thought-energy to convert the idea to use in his own classrooms. The multi-day workshop format, then, can help turn what could be intransigent resistance into a healthy stage on the way to substantive change.

\section{From the Ground Up: Effective Structuring}

Plenty of time and talk will not, of course, inevitably lead to transformative reconceptions of teaching and learning. Effective structure is needed. The week-long workshops I have helped to design at Virginia Tech borrow from the "ground up" structure of other successful WAC programs around the country. That is, rather than throw teaching tips and techniques at teachers, our workshops begin by considering our fundamental assumptions about teaching and learning, their connection to current research in the educational field, and their manifestation on that ultimate pedagogical statement, the course syllabus. Participants write about their assumptions, their images of students, their goals and motivations as teachers. They examine their own syllabi, working to more clearly articulate learning objectives and to structure the semester in ways that move beyond "calendars of coverage" to organized, sequenced explorations of critical course issues. They next work to design and link assignments that are clearly tied to course objectives. Finally, they create supportive in- and out-of-class activities to develop the critical competencies that students will need to complete major assignments successfully. 
Each participant targets a specific course to work on throughout the week. Prior to the first day, each has chosen a course and begun actively considering how to revise it. This project orientation allows participants to focus on specific outcomes from the beginning as they translate and integrate workshop insights into their own contexts. The ground-up structure ensures that each teacher critically examines all aspects of the chosen course and of the learning environment that it creates. Not infrequently, such an examination reveals fundamental problems or contradictions at some level. It may be that there are poorly articulated learning objectives for coursework, unengaging or ill-defined assignments, or classroom activities that do not correspond to current research on effective learning strategies. This lengthy, structured examination often leads to troubling discoveries that can only be addressed through fundamental change.

Participants are motivated principally by knowledge that they are altering an important course of their own choosing. A more immediate motivation to commit to change is the final day of presentations. Here, each presents to the group the specific course changes he or she has made as a result of the week of study and collegial interaction. For some the change is a seemingly small, yet significant step, such as using writing in a mathematics classroom for the first time. For others, the change is elemental, as when a veteran Virginia Tech history professor this past summer described a series of epiphanies that enabled him to radically revise his course's goals, foci, methodologies, organization of material, writing assignments and tests. Subsequently, he recalibrated his grading system.

\section{Making the Right Investment}

At least two important areas in faculty development might usefully apply the lessons of the well-conceived, multi-day WAC workshops I have championed. Technology training is the first area. As academic institutions increasingly invest in the exploding field of instructional technologies, they need to help educate faculty in their wise use. Here, as with writing, our initial focus on a particular area leads to an examination of the whole enterprise of teaching and learning. Employing new technologies can fundamentally change 
teaching environments and alter pedagogies. Used without serious consideration or careful integration into informed teaching approaches, technology will alter pedagogies for the worse. Institutions need more than two-hour workshops on PowerPoint or the use of web chats. Sustained multidisciplinary workshops of the kind described in this article may be our most effective way to ensure that our technology investment yields the best fruits for teachers and students.

Another important development is the increasing call for interdisciplinary collaboration. While many academic institutions have interdisciplinary programs, many more are forming, and difficult budgetary times have impelled some administrators to combine traditionally discrete colleges or departments. Many see great promise in the move toward a learning environment without rigid disciplinary boundaries. Faculty forums and task forces are typically organized to help once separate units begin to work together to establish joint objectives and develop innovative new educational avenues for undergraduates. But the task is sizable in an academic culture that has traditionally bred a narrowness of concern and a turf-protection mentality. Occasional meetings held in the midst of busy schedules are unlikely to help faculty address the complexities of these new relationships and new structures. The WAC workshop model described here offers a better chance for transformative interdisciplinary collaboration.

The big picture is both exciting and disconcerting. The difficulty is that the renewed emphasis on teaching and newer commitments to technology and interdisciplinarity come at a time of great financial challenge for institutions of higher education. The message is not one that will be easy for administrators to hear and to act on, but the fact remains: substantive faculty development requires significant time, careful planning, and considerable financial investment. Despite shrinking budgets, the urge to cut more expensive faculty development efforts like the multi-day WAC workshop must be resisted if we are truly interested in taking a hard look at the culture of education and positively transforming the learning experience for both teachers and students. Faculty development efforts that only deliver teaching tips or practice running the latest software applications won't do. Our faculty members need structured time to think and to plan-both 
individually and collectively - if they are to go forth better prepared to educate tomorrow's citizens and workers for a challenging and complex new century.

\section{References}

Angelo, T. A. (1994, Jume). From faculty development to academic development. American Association for Higher Education Bulletin, 46, 3-7.

BeMiller, S. (1990). California State University, Chico. In T. Fulwiler \& A. Young (Eds.), Programs that work: Models and methods for writing across the curriculum (pp. 115-136). Portsmouth, NH: Heinemann.

Crawley, A. L. (1995) Faculty development programs at research universities: Implications for senior faculty renewal. In L. Neal (Ed.), To Improve the Academy, Vol. 14, (pp. 65-90). Stillwater, OK: New Forums Press and the Professional and Organizational Development Network in Higher Education.

Dickerson, M., Fulwiler, T., \& Steffens, H. (1990). The University of Vermont. In Fulwiler and Young (Eds.), Programs that work: Models and methods for writing across the curriculum (pp.115-136). Portsmouth, NH: Heinemann.

Fulwiler, T., Gorman, M., \& Gorman, M. (1986). Changing faculty attitudes toward writing. In Young and Fulwiler (Eds.), Writing across the disciplines: Research into practice (pp. 53-65). Portsmouth, NH: Heinemann.

Kipling, K., \& Murphy Jr., R. J. (1992). Symbiosis: Writing and an academic culture. Portsmouth NH: Heinemann.

Magnotto, J. (1990). Prince George's Community College. In Fulwiler and Young (Eds.), Programs that work: Models and methods for writing across the curriculum (pp. 115-136). Portsmouth, NH: Heinemann.

Palmer, P. (1993). Good talk about good teaching: Improving teaching through conversation and community. Change, 6, 8-14.

Qualters, D. (1995) A quantum leap in faculty development: Beyond reflective practice. In L. Neal (Ed.), To Improve the Academy, Vol. 14, (pp. 43-55). Stillwater, OK: New Forums Press and the Professional and Organizational Development Network in Higher Education.

Contact:

Jim Laughlin

Linkage, Incorporated

One Forbes Road

Lexington, MA 02173

(617) 401-1715

(617) 860-5138 FAX 
Jim Laughlin recently joined Linkage, Incorporated, a corporate education and organizational management consulting firm. He was a member of the English Department at Virginia Polytechnic Institute and State University from 1990-1996, where he helped to establish The University Writing Program, Virginia Tech's writing across the curriculum program. 


\section{Appendix}

\section{Writing Across the Curriculum Resources}

Fulwiler, T. (1994). How well does writing across the curriculum work? College English, 46, 113-125.

Fulwiler, T., \& Young, A. (1990). Programs that work: Models and methods for writing across the curriculum. Portsmouth, NH: Heinemann.

Griffin, C. W. (1983). Using writing to teach many disciplines: A process to critical thinking. Improving College \& University Teaching, 31, 121-128.

Herrington, A., \& Moran, C. (1992). Writing, teaching, and learning in the disciplines. New York: The Modern Language Association of America.

Hult, C. A. (1996). Researching and writing across the curriculum. Needham Heights, MA: Allyn \& Bacon.

Jones, R., \& Comprone, J. (1993). Where do we go next in writing across the curriculum? College Composition and Communication, 44, 59-68.

Mahala, D. (1991). Writing utopias: Writing across the curriculum and the promise of reform. College English, 53, 773-789.

Walvoord, B. (1996). The Future of WAC. College English, 58, 5879.

Young, A., \& Fulwiler, T. (Eds.). (1986). Writing across the disciplines: Research into practice. Portsmouth, NH: Heinemann. 